\title{
RETENÇÃO DA ÁGUA DA CHUVA PELO TELHADO VERDE COM PRÉ-MOLDADO CIMENTÍCIO COM EVA
}

\section{RAINWATER RETENTION BY GREEN ROOF WITH PRECAST CEMENTITIOUS WITH EVA}

\author{
Tatyane Nadja Martins de Mendonça 1 \\ Secretaria de Educação do Estado da Paraíba, João Pessoa, Paraíba, Brasil, tatyanemartinn@gmail.com \\ Aluísio Braz de Melo ${ }^{2}$ \\ Universidade Federal da Paraíba, João Pessoa, PB, Brasil, aluisiobmelo@homail.com
}

\begin{abstract}
Resumo
Os problemas de inundação nas vias urbanas, decorrentes da combinação da ocorrência de fortes chuvas e excesso de impermeabilização dos espaços urbanos, têm causado sérios prejuízos às cidades brasileiras. O telhado verde com sua capacidade de retenção da água de chuva é uma interessante alternativa para reduzir as descargas nos sistemas de drenagem urbana. No presente artigo, procura-se analisar o potencial de retenção dessas águas, a partir de um telhado verde, proposto com prémoldados cimentícios com agregados leves de Etileno Vinila de Acetato (EVA), originados de resíduos da indústria de calçados. Para isso, foram comparados resultados a partir de monitoramentos dos volumes de chuvas sobre o telhado verde proposto e coberturas convencionais, todos instalados em protótipos. Adicionalmente, foi feita simulação para estimar a capacidade de retenção das águas de chuvas num cenário hipotético, no qual uma pequena parcela das coberturas das edificações da cidade fosse instalada o telhado verde proposto. A contribuição adicional na retenção das águas de chuvas devido à presença dos agregados leves nos módulos foi confirmada. Também foi demonstrada que a capacidade de retenção da água de chuva pelo telhado verde proposto pode variar entre $73,3 \%$ e 90,5\%, conforme o solo esteja seco ou úmido, respectivamente. Os volumes de retenção estimados na simulação para a cidade podem ser de até 4 milhões de litros/dia na condição de solo seco no telhado verde, o que indica que, caso este tipo de cobertura seja incentivado nas edificações, há potencial para mitigar os problemas de enchentes nas vias da cidade.
\end{abstract}

Palavras-chave: Agregados leves. Água de chuva. Pré-moldados. Resíduos EVA. Telhado verde.

\begin{abstract}
Flooding problems in urban streets, resulting from the combination of occurrence of heavy rains and excess sealing of urban spaces, have caused severe losses to Brazilian cities. The green roof with your rainwater retention capacity is an interesting alternative to reduce the discharges on urban drainage systems. In this article, we will analyze the rainwater retention potential, from an extensive modular green roof, proposed with precast cementitious with lightweight aggregates of Ethylene Vinyl Acetate (EVA), originated from footwear industry waste. For this, were compared results from monitoring the volumes of rainfall over the proposed green roof and conventional roofing, all installed on prototypes. Additionally, a simulation was performed to estimate the rainwater retention capacity in a hypothetical scenario, in which a small portion of the city's buildings covers were installed green roof proposed. The additional contribution to rainwater retention due to the presence of lightweight aggregates on the modules was confirmed. It has also been demonstrated that the rainwater retention capacity by green roof proposed may vary between $73.3 \%$ and $90.5 \%$, as the soil is wet or dry, respectively. The retention volumes estimated in the city's simulation can be up to 4 million liters/day in dry conditions on the green roof. Indicating that this type of coverage is encouraged in buildings; there is the potential to mitigate flooding problems on city roads.
\end{abstract}

Keywords: Lightweight aggregates. Rainwater. Precast. EVA waste. Green roof.

How to cite this article:

MENDONÇA, T. M.; MELO, A. B. Retenção da água da chuva pelo telhado verde com pré-moldado cimentício com EVA. PARC Pesquisa em Arquitetura e Construção, v. 11, p. e020007, 29 maio 2020. ISSN 1980-6809.

DOI:https://doi.org/10.20396/parc.v11i0.8651659 


\section{Introdução}

Os telhados verdes correspondem ao cultivo de vegetais nas coberturas das edificações, compostos basicamente por um sistema que inclui impermeabilização, elementos de drenagem, membrana de retenção de substrato (membrana filtrante), e por fim, o substrato e a vegetação (CASTLETON et al., 2010).

Sabe-se que existem algumas características discutidas na literatura com relação às instalações dos telhados verdes, e dentre eles pode-se destacar três aspectos fundamentais: 1 - aqueles inerentes ao aumento da inércia térmica (BERARDI; GHAFFARIANHOSEINI; GHAFFARIANHOSEINI, 2014; CASTLETON et al., 2010; JAFFAL; OULDBOUKHITINE; BELARBI, 2012; DEL BARRIO, 1998; THEODOSIOU, 2003; NIU et al., 2010; OULDBOUKHITINE et al., 2011; VECCHIA, 2005); 2 - aqueles referentes à disponibilidade de novos habitats, que favorecem a biodiversidade do entorno (WILLIAMS; RAYNER; RAYNOR, 2010; OBERNDORFER et al., 2007; KÖHLER, 2006; KÖHLER; POLL, 2010; TONIETTO et al., 2011; DUNNETT; NAGASE; HALLAM, 2008; BERARDI; GHAFFARIANHOSEINI; GHAFFARIANHOSEINI, 2014); e 3 - aqueles relativos à capacidade do sistema de telhado verde reter água de chuva, cujas referências são tratadas no presente artigo.

Com relação ao último aspecto fundamental referido, a própria composição orgânica do sistema é responsável pelo efeito de retenção das águas de chuvas, uma vez que inicialmente é preciso que o solo com a vegetação atinja um estágio de saturação, para então começar a liberar a água excedente para a rede coletora da edificação e, posteriormente, encaminhamento para o sistema de drenagem urbana. Desse modo, se usado em larga escala nas coberturas das edificações, certamente, o somatório das contribuições parciais de cada cobertura vegetada reduziria, significativamente, as descargas de águas de chuvas no sistema de drenagem urbana e, possivelmente, os riscos de enchentes das vias da cidade. Isto é frequente, sobretudo naqueles momentos de alta precipitação pluviométrica, em curto espaço de tempo, favorecida por determinado microclima urbano, quando é maior a vazão das águas de chuvas nas superfícies do solo, cada vez mais impermeabilizadas, resultando em rápido deslocamento das águas para as partes mais baixas do espaço urbano.

Mentens, Raes e Hermy (2006) afirmam que, considerando uma projeção anual, a relação entre precipitação pluviométrica e escoamento das águas de chuva pelos telhados verdes é fortemente influenciado pela profundidade (espessura) da camada de substrato desse telhado. Também afirmam que a retenção da água da chuva em telhados verdes é menor na estação de inverno do que na de verão. Entende-se que os autores estão se referindo àquelas regiões em que o inverno é caracterizado como período chuvoso e o verão como período com baixa precipitação pluviométrica. Para Mentens, Raes e Hermy (2006), tal relação se justifica pelo fato de que durante o verão, devido à ocorrência de chuvas intercaladas com dias ensolarados, nessa última condição, o substrato acaba perdendo umidade rapidamente, com a evaporação da água retida, e com isso, se mantém a sua alta capacidade de retenção das águas de chuvas na ocorrência das próximas chuvas. Já no inverno, o substrato se mantém sempre mais úmido e, dessa forma, tende a perder sua capacidade de retenção da água da chuva.

Além da espessura do substrato, outros fatores influenciam no coeficiente de escoamento superficial, tais como: a inclinação e o tipo de vegetação do telhado (OHNUMA, 2008). Van Woert et al. (2005) desenvolveram um estudo comparativo com três tipos de coberturas sobre plataformas (uma com lastro de brita e dois telhados verdes extensivos sem e com vegetação, respectivamente), no qual se constatou a mais 
alta retenção das águas da chuva para o telhado verde com vegetação (82,8 \%). Ainda de acordo com o estudo, a combinação entre plataformas com inclinação de $2 \% \mathrm{e}$ profundidade média de $4 \mathrm{~cm}$ para as coberturas testadas resultou na maior retenção média ( $87 \%$ ) da água da chuva.

Nos estudos desenvolvidos por DeNardo et al. (2005), os telhados verdes experimentais compostos por várias camadas (barreira anti raiz; drenagem -1,2 cm; solo/substrato - 8,9 $\mathrm{cm}$; material poroso à base de polipropileno expandido $-2,5 \mathrm{~cm}$ e vegetação $-7,6 \mathrm{~cm})$, aplicados em coberturas planas de três edifícios, foram monitorados durante 7 (sete) eventos de chuvas, em dois meses, cujo dados permitiram verificar a capacidade de retenção das águas de chuvas. Constatou-se que os telhados verdes se mostraram com capacidade de reter, em média, 45\% (19\% a 98\% de intervalo) das águas das chuvas.

Tassi et al. (2014) avaliaram o escoamento superficial das águas de chuva, durante 17 meses, numa mesma construção, com metade da cobertura com telhas de fibrocimento (telhado convencional) e a outra metade com telhado verde extensivo, que foi composto por módulos pré-fabricados $(70 \mathrm{~cm} \times 35 \mathrm{~cm} \times 9 \mathrm{~cm}$; comprimento $\times$ largura $\times$ altura), contendo 8 células, executados com compósito cimentício com EVA reciclado moído. A profundidade do solo dentro de cada célula era igual a $8 \mathrm{~cm}$. Eles constataram que houve redução, em média $62 \%$, dos volumes de águas escoadas superficialmente com a utilização do telhado verde. Concluíram ainda que a capacidade de armazenamento da água da chuva pelo telhado verde testado foi influenciada pelas condições climáticas e pela umidade antecedente do solo, confirmando dados da literatura.

Jobim (2013) fez um estudo comparativo entre alguns sistemas de telhados verdes extensivos comerciais, buscando identificar diferenças na capacidade de retenção da água de chuva. Nesse estudo, foi incluído, entre os sistemas de telhado verde comparados, um que utiliza um módulo pré-fabricado, cujas unidades modulares possuem uma estrutura base para receber o substrato e vegetação, executado com compósito cimentício com agregados leves de Etileno Vinila de Acetato (EVA), originado de resíduos da indústria de calçados. Utilizou-se como aglomerante o cimento Portland de alta resistência inicial ( $C P \vee A R I)$, com adição de cinzas volantes. O módulo contém oito células, dentro das quais foram colocados o substrato e a vegetação. Trata-se do mesmo módulo avaliado no estudo de Tassi et al. (2014).

De acordo com os resultados obtidos por Jobim (2013), o sistema de telhado verde mais eficiente foi aquele utilizando os módulos cimentícios com agregados de EVA, cujo substrato foi realizado parcialmente com argila expandida (apesar de a altura possível ser até $8 \mathrm{~cm}$, no experimento foi preenchido com substrato até $3 \mathrm{~cm}$, quando utilizou argila expandida, e $4 \mathrm{~cm}$ sem argila expandida), o que contribuiu para reduzir, em média $88,1 \%$ do escoamento superficial da água de chuva. Para o mesmo sistema sem a argila expandida, a redução média foi de $82,8 \%$. Esse sistema apresentou maior capacidade de retenção de água da chuva, e menor perda de eficiência à medida que os volumes de chuva aumentaram. Ainda segundo o mesmo autor, a mais alta capacidade de retenção de água de chuva para esse sistema também se deve à composição do próprio módulo, sobretudo devido à presença dos agregados leves de EVA, que é conhecido como um material com alta capacidade de absorção de água.

Tendo em vista as questões relacionadas à capacidade de retenção da água de chuva de diferentes coberturas aqui tratadas, neste artigo apresentam-se os resultados de um estudo sobre a estimativa da água de chuva que é retida por um sistema de telhado verde modular extensivo, comparado a diferentes tipos de coberturas convencionais, todos executados em pequena escala. Neste estudo, procurou-se analisar o potencial 
de retenção de água da chuva pelo telhado verde proposto, cujo monitoramento foi realizado numa condição de baixa quantidade de chuvas locais, típica do verão na cidade (João Pessoa-PB). Em seguida, foram feitas simulações para os volumes de retenção de água de chuva, num cenário para a mesma cidade, localizada no litoral do nordeste brasileiro, admitindo-se a hipótese de que uma pequena parcela das coberturas das edificações verticalizadas (tipo multi pavimentos), construídas nessa cidade, seja executada com o telhado verde modular extensivo proposto.

\section{Procedimentos metodológicos}

No presente estudo, foi avaliada a capacidade de retenção das águas de chuva pelo telhado verde modular extensivo, cujos módulos são blocos pré-moldados cimentícios leves ( $30 \mathrm{~cm} \times 30 \mathrm{~cm} \times 13 \mathrm{~cm}$; comprimento x largura x altura), fabricados com resíduos da indústria de calçados (Etileno Vinila de Acetato- EVA), aqui denominado como bloco TEVA (MENDONÇA, 2015; MENDONÇA; MELO, 2017). Cada módulo tem sua geometria configurada com 4 (quatro) células (altura $=10 \mathrm{~cm}$ ), para receber substrato e vegetação (Figura 1). Uma característica interessante do bloco TEVA, que foi fabricado com dosagem de 1:5 (cimento: agregados; em volume), com 90\% de EVA e 10\% de areia, é sua alta permeabilidade à água (Figura 1 - a direita), que possibilita a drenagem do excesso de água, eventualmente, acumulada no substrato durante o período muito chuvoso, que pode ser desfavorável às raízes da vegetação. Figura 1 - Bloco TEVA proposto com 4 (quatro) células para receber substrato e vegetação: (a esquerda) desenho do bloco TEVA (medidas em cm),
(ao centro) penetração de água ao iniciar submersão em água e (a direita) drenagem da água ao ser retirado do tanque
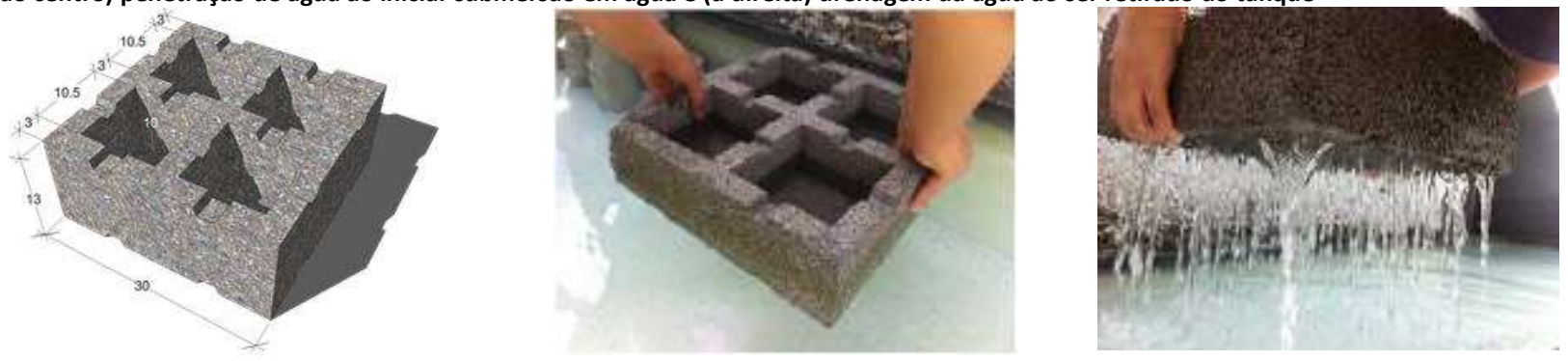

Fonte: Os autores.

Os tipos de coberturas comparadas nesse estudo foram simulados, em escala reduzida, em cinco protótipos construídos no mesmo local, com dimensões internas iguais, 1,0 m x 1,0 m x 1,0 m (largura x comprimento x altura - Figura 2 - a esquerda) e com os mesmos materiais aplicados nos planos verticais (paredes com tijolo cerâmico revestidas com argamassa em ambos os lados) e nos planos horizontais (piso cimentado e laje prémoldada convencional com inclinação de $2 \%$ e impermeabilizada com tinta acrílica). Neste caso, 2 (dois) protótipos receberam coberturas convencionais (um com telhas de fibrocimento - P2; e outro com telhas cerâmicas - P3, apoiadas diretamente sobre a laje) e outros 2 (dois) receberam telhados verdes (um com os blocos TEVA - P5; e outro com os blocos de concreto - $\mathrm{P} 4$, que têm a mesma geometria do bloco TEVA) também sobre a laje. Outro protótipo (P1) foi deixado com a laje exposta e impermeabilizada como referência, para efeito dos cálculos relativos das capacidades de retenção de água da chuva de cada cobertura com telhas e com telhados verdes (Figura 3).

O procedimento adotado no estudo tem como base um processo simplificado para registros das quantidades de água de chuva escoada pelos diferentes tipos de coberturas sobre os protótipos, sob as mesmas condições de exposições ao clima local. Para isso, foi instalado em cada protótipo um sistema de coleta de água da chuva (Figura 2 - ao centro) com calha, tubos e conexões em PVC, conectados a coletores (depósitos de plástico com capacidade de 23 litros), com escala definida para facilitar o 
monitoramento diário (Figura 2 - a direita), com registro dos volumes sempre no mesmo horário (7 horas da manhã), durante o período de 36 dias (17-jan-2015 até 21-fev-2015). Considerando a área da cobertura do protótipo $(1,77 \mathrm{m2})$ e a baixa intensidade das chuvas locais, no período de monitoramento (estação de verão), na maioria dos casos, o volume dos recipientes de plásticos foi suficiente para acumular água coletada dos telhados e permitir os registros diários. De fato, ver-se que os volumes de chuva são muito baixos nesse período (janeiro e fevereiro) em João Pessoa-PB, a partir da série histórica de 10 anos (2002/2011) dos registros do Instituto Nacional de Meteorologia (INMET), publicados no estudo feito por Diniz (2013), quando a média diária de chuvas corresponde a $3,5 \mathrm{~mm} /$ dia (janeiro) e 4,7 mm/dia (fevereiro).

Figura 2 - Protótipo construído com sistema de coleta da água de chuva da cobertura: (a esquerda) desenho em corte do protótipo, (ao cen tro) vista da calha, tubo, conexões e depósito para armazenar água da chuva escoada pela cobertura e (a direita) detalhe da escala definida no depósito para facilitar leitura diária dos volumes de água de chuva
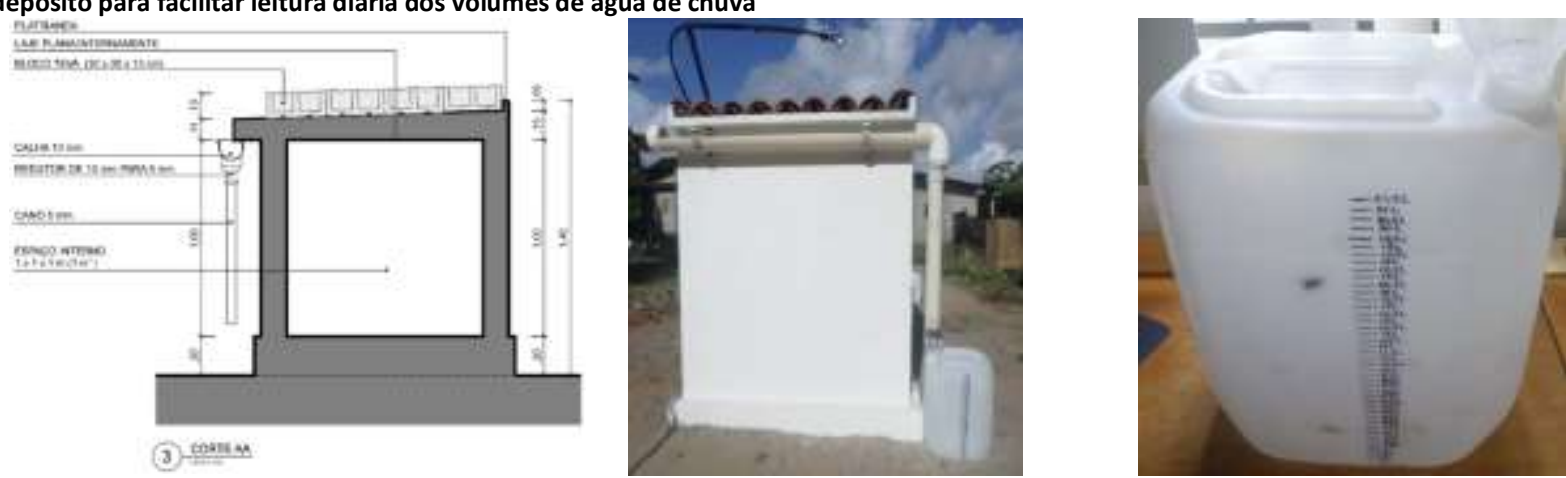

Fonte: Os autores.

Figura 3 - Protótipos com as 5 (cinco) coberturas diferentes, posicionados para os monitoramentos durante as ocorrências de chuvas: (a esquerda acima) imagem dos protótipos construídos, (ao centro acima) telhado verde com blocos TEVA (P5), (a direita acima) telhado verde com bloco de concreto (P4) e (abaixo) planta de locação e coberta dos cinco protótipos com as distâncias (2,70 m) entre eles
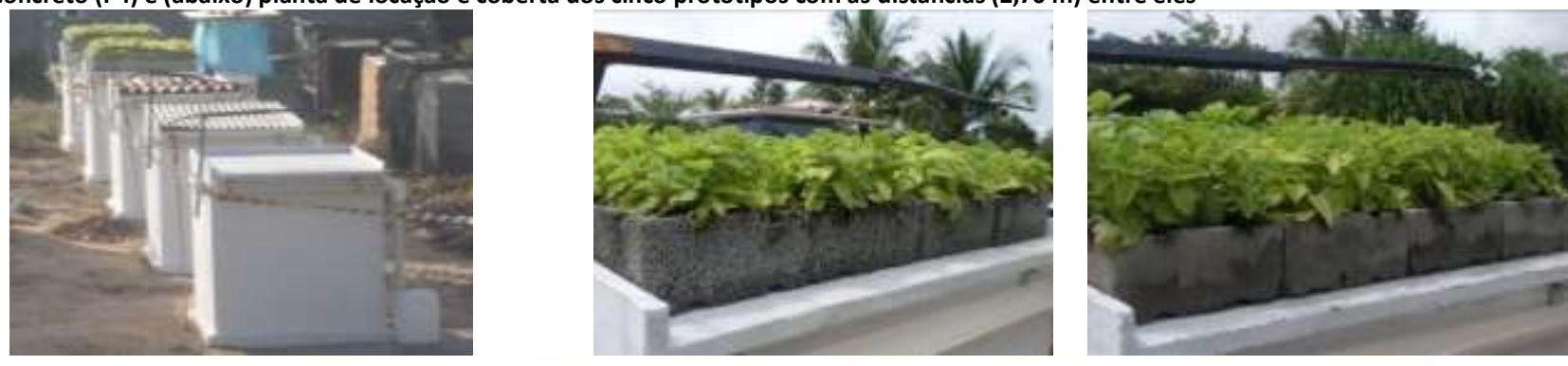

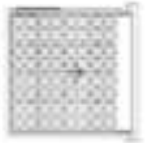

P5

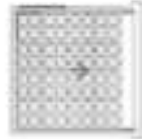

$\mathrm{P}_{4}$

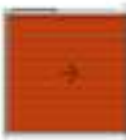

P3

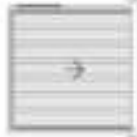

$p_{2}$

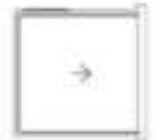

Fonte: Os autores

Cabe ressaltar que os telhados verdes instalados em cada protótipo (ambos com o mesmo tipo de vegetação, que é hortelã da folha graúda), um deles executado com blocos TEVA (Figura 3 - ao centro acima) e outro executado com blocos de concreto (Figura 3 - a direita acima), permitiram identificar a contribuição isolada da presença dos agregados EVA (resíduos da indústria de calçados) na capacidade de retenção das águas pluviais, na medida em que a única diferença entre os dois telhados verdes passou a ser apenas pela presença e ausência dos agregados de EVA nos blocos (módulos).

Destaca-se que somente aquela cobertura executada com os blocos TEVA propostos atende aos requisitos de sistema de telhado verde extensivo modular, que segundo 
Berardi, Ghaffarianhoseini e Ghaffarianhoseini (2014) deve ser um sistema mais leve, com sobre carga máxima na laje limitada até $150 \mathrm{~kg} / \mathrm{m} 2$, que utiliza plantas de pequeno porte e tem o processo construtivo facilitado, com baixo custo, e simplificada manutenção, com pouca necessidade de irrigação.

Outra questão interessante é que a partir do ensaio de absorção de água dos componentes (módulos), segundo a NBR 12118 (ABNT, 2014), executados com cada compósito cimentício, foi possível identificar uma diferença importante entre eles. $\mathrm{O}$ bloco TEVA teve absorção de água média igual a $19,5 \%$, cerca de três vezes maior do que o bloco de concreto (absorção de água média igual a 6,2\%).

Durante o período de monitoramento adotado no presente estudo foram feitos registros diários dos valores coletados nos depósitos de plástico, que traduzem de forma simplificada e comparativa aquela parcela da água da chuva escoada através de cada cobertura. Nesse período, foram identificados apenas 10 dias que tiveram ocorrência de chuva no local, com volumes pequenos e diferenciados.

O monitoramento diário da quantidade de água da chuva escoada pelas diferentes coberturas teve como referência os procedimentos adotados no estudo de Jobim (2013), no qual foram utilizados recipientes (coletores) semelhantes para fins comparativos. No presente estudo, nos cinco (5) recipientes (um para cada protótipo) foram desenhadas escalas com precisão de 0,5 , sendo a capacidade total de cada recipiente igual a 23 litros (Figura 2 - a direita).

A partir dos registros (em litros) da água da chuva que se considera escoada pelos diferentes tipos de coberturas (a partir dos volumes acumulados pelos respectivos recipientes) foi possível constatar os volumes/dia e os dias de ocorrência de chuvas no local. Tais dados posteriormente foram confirmados pelos dados pluviométricos (em milímetros acumulados por dia) registrados pela mini estação meteorológica (Wireless Vantage Pro2 ${ }^{\mathrm{TM}}$ with Standard Radiation Shield; Davis Instruments Corp., 2012), devidamente instalada nas proximidades dos protótipos (junto ao abrigo na cor azul, visto ao fundo na Figura 3 a esquerda acima) onde foram colocados os equipamentos eletrônicos.

Com os dados pluviométricos registrados pela mini estação meteorológica foi utilizado o procedimento de chuva acumulada em 24 horas, para facilitar a comparação com os dados obtidos a partir dos registros da água escoada pelas coberturas dos protótipos. Dessa forma, os registros ficaram compatíveis, visto que o registro da coleta dos dados nos protótipos só se dava uma vez ao dia, especificamente às 7 horas da manhã, e por isso, só foi possível identificar o volume de chuva acumulada também a cada 24 horas.

Os registros dos valores da água da chuva escoada pelos telhados dos protótipos com diferentes coberturas foram sistematizados em planilha eletrônica (para posterior elaboração de gráficos), considerando inicialmente os correspondentes volumes (em litros) de chuva/dia e, posteriormente, dividindo-os pela área efetiva da cobertura do protótipo $(1,77 \mathrm{~m} 2)$, cujos resultados passaram a ter a unidade representada por (litros/dia)/m2. Desse modo, tem-se a uniformização das unidades (mm/dia) adotadas para o índice pluviométrico determinado, o qual se refere à quantidade de chuva por metro quadrado em determinado local e período. Para tal uniformização, adota-se também o conceito de que cada litro corresponde a 1 (um) $\mathrm{mm}$ em medidas pluviométricas.

Entre os 10 (dez) eventos de chuva registrados, em dois deles (17-jan-2015 e 20-fev-2015) ocorreram volumes que devem ter superado a capacidade do depósito coletor (23 litros), instalado no protótipo com laje exposta, exatamente aquela cobertura onde o 
escoamento da água da chuva é máximo, cujos valores foram adotados como referência nos cálculos. Portanto, só foram aproveitados os registros das chuvas para os demais 8 (oito) dias monitorados, a partir dos quais foi possível identificar dois dias específicos (29-jan-2015 e 21-fev-2015) e bem distintos em relação aos volumes de chuva/dia (2,6 mm e $6,6 \mathrm{~mm}$, respectivamente) acumulados e aos respectivos períodos antecedentes ( 3 a 4 dias anteriores), com e sem ocorrência de chuvas. Ainda que ambos os volumes de chuva/dia sejam baixos, como é característica do clima local para o período, tais variações identificadas nestes volumes de chuva no local tornaram possível se fazer uma análise para o telhado verde, admitindo-se a condição para o solo úmido associado ao dia com maior volume de chuva e com chuva nos 4 dias antecedentes; e para o solo seco associado ao dia com menor volume de chuva e sem chuva nos 3 dias antecedentes. Dessa forma, foi possível calcular os diferentes percentuais de escoamento da água de chuva para cada tipo de cobertura (Telhado verde com blocos TEVA, Telhado verde com blocos concreto, telha cerâmica e telha fibrocimento), para diferentes condições de umidade nos materiais presentes nas respectivas coberturas.

O cálculo do percentual de escoamento superficial de água da chuva por cada tipo de cobertura (com telhas e com telhado verde) foi realizado considerando a relação entre o valor de água escoada em cada uma delas e aquele volume máximo que foi escoado pela laje exposta e impermeabilizada, reconhecendo-se que há a mesma condição de exposição às chuvas locais para todos os protótipos. Nessa análise, procurou-se identificar a contribuição adicional do agregado de EVA, a partir da comparação específica entre os valores determinados para os dois telhados verdes em teste (blocos TEVA x blocos concreto).

Com os valores obtidos para aqueles dois dias característicos, que representam a condição com os materiais das coberturas (solo e telhas) úmidos e secos, respectivamente, procurou-se analisar comparativamente o escoamento superficial da água de chuva pelas coberturas nos protótipos, dando destaque para o telhado verde com blocos TEVA executado em um deles.

A partir do percentual de escoamento superficial calculado para o telhado verde com bloco TEVA, determinou-se o equivalente coeficiente de escoamento superficial (CES), abstraindo-se de outras variáveis envolvidas (ex.: evapotranspiração) e lembrando que os valores são relativos ao volume máximo de água escoada pela laje exposta e impermeabilizada.

Para avaliar as simulações de volumes de retenção de água de chuva num cenário de uma cidade de porte médio, localizada no litoral do nordeste brasileiro, selecionou-se João Pessoa-PB (coordenadas geográficas: $7^{\circ} 9^{\prime} 58^{\prime \prime}$ '; 34 48'58”W) para exemplificar, sendo importante para análise dessas simulações a caracterização do clima e do regime de chuvas locais. Assim, em relação ao clima pode-se dizer que é quente e úmido, com maiores volumes de chuvas durante o outono e o inverno e com $25^{\circ} \mathrm{C}$ de temperaturas médias anuais e $80 \%$ de média da umidade relativa do ar. Na série histórica de 10 anos, entre 2002 e 2011, dos registros do INMET, publicados no estudo feito por Diniz (2013), tem-se uma média diária de precipitação pluvial em João Pessoa-PB igual a 5,5 mm/dia, com destaque para períodos de baixas precipitações entre os meses de outubro a dezembro, enquanto o mês de junho se caracteriza como o mais chuvoso.

Na simulação dos volumes de água de chuva retidos foram admitidas algumas hipóteses para a elaboração dos cálculos e análises feitas apenas para o telhado verde com blocos TEVA proposto. Inicialmente, a aplicação desse telhado verde seria apenas numa pequena parcela do total das edificações da cidade, que nesse caso seriam apenas aquelas edificações com alta e muito alta densidade por lote, cuja cobertura é executada 
normalmente com telha fibrocimento ou com laje exposta impermeabilizada. Então, foram consideradas suas respectivas áreas de projeção, ou seja, 3,12\% da área total de coberturas das construções na cidade, que corresponde a $6,58 \mathrm{~km} 2$, cujos valores foram aproveitados do estudo sobre a construção/atualização do mapa climático de João Pessoa-PB (RIBEIRO, 2013), no qual foram produzidos vários mapas intermediários, dentre os quais o mapa de volume construído, a partir do levantamento fotogramétrico de 2012, realizado pela prefeitura da cidade.

Neste mapa de volume construído, Ribeiro (2013) considerou a área de projeção das construções e a altura das edificações para determinar 4 (quatro) faixas com densidades construídas distintas (baixa, média, alta e muito alta), as quais foram correlacionadas diretamente com cargas térmicas do ambiente construído e seu impacto no mapa climático da cidade. Em seu estudo, considerando a projeção das construções (em m2), existentes em 2012, constatou que aproximadamente $48 \%$ da área do território municipal correspondiam a edificações, sendo 40,75\% (85,99 km2) com baixa densidade, 3,68\% (7,77 km2) com média densidade, 2,28\% (4,81 km2) com alta densidade e 0,84\% $(1,77 \mathrm{~km} 2)$ com muito alta densidade.

Portanto, na simulação realizada para analisar a capacidade de retenção das águas pluviais pelo telhado verde com blocos TEVA propostos, os dados quantitativos referidos foram associados como área de captação de água de chuva possível nos cálculos. Contudo, foram levadas em conta apenas aquelas parcelas correspondentes às coberturas das edificações (ou área de projeção das construções), com alta e muito alta densidade por lote, que totalizam apenas 3,12\% (6,58 km2 ou $6.580 .000 \mathrm{m2})$ da área do território municipal, ou seja, entende-se essa parcela como sendo referente às projeções das edificações verticalizadas, com mais de 4 pavimentos.

Nos cálculos da simulação referida, foi adotado também que apenas 30\% das edificações verticalizadas (tipo multi pavimentos), adotariam substituição das telhas de fibrocimento (ou laje exposta impermeabilizada) por telhado verde modular extensivo proposto, ou seja, cerca de $1.974 .000 \mathrm{~m} 2$. Também foi adotado que os telhados verdes normalmente ocupam parcialmente as coberturas, sendo considerado nesse caso ocupação de apenas $40 \%$, ou seja, 789.600 m2. Então, esse último valor foi considerado nos cálculos como área de captação da chuva nessa simulação, que multiplicado pela média diária de precipitação pluvial na cidade $(5,5 \mathrm{~mm} / \mathrm{dia})$ resultou na estimativa do volume de água de chuva incidente sobre o hipotético telhado verde TEVA, que ocuparia parcialmente as coberturas de alguns edifícios (Tabela 1).

Para estimar o volume da água de chuva que seria aproveitável ou, no caso específico, escoada pelo telhado verde das edificações utilizadas na simulação, foi utilizada uma adaptação da equação (eq. 01) adotada para efeito do dimensionamento de reservatório de água de chuva, prevista no anexo A.1 da NBR 15527 (ABNT, 2007), que se baseia no Método de Rippl. Note-se que na equação podem-se usar as séries históricas mensais ou diárias das precipitações das chuvas locais, sendo adequada para os cálculos aqui realizados.

$$
Q(t)=C x \text { precipitação da chuva }(t) x \text { área de captação }
$$

onde:

- $\mathrm{Q}(\mathrm{t})$ é o volume de chuva aproveitável ou escoada (litros/dia) no tempo t (24 horas);

- C é o coeficiente de escoamento superficial;

- Precipitação da chuva = média diária da chuva local, expressa em “mm/dia"; 
- Área de captação = área de telhado verde TEVA executado parcialmente nas coberturas das edificações na cidade, expressa em "m2";

Tabela 1 - Estimativa do volume de água de chuva incidente sobre o hipotético telhado verde TEVA, simulado nas coberturas de parte dos edifícios de João Pessoa-PB

\begin{tabular}{|c|c|c|c|}
\hline Dados e hipóteses consideradas & & & Fonte: \\
\hline A - Média diária da precipitação pluviométrica (série 2002-2011) & 5,5 & $\mathrm{~mm} / \mathrm{dia}$ & Diniz (2013) \\
\hline $\begin{array}{l}\text { B - Área de projeção dos edifícios (com alta e muito alta densidade por lote) } \\
\text { correspondente às coberturas (3,12\% da área da cidade) }\end{array}$ & 6.580 .000 & $\mathrm{~m}^{2}$ & Ribeiro (2013) \\
\hline $\begin{array}{c}\text { C - Edificações que adotariam substituição da laje exposta impermeabilizada } \\
\text { por telhado verde TEVA; } 30 \% \text { da área de "B" }\end{array}$ & 1.974 .000 & $\mathrm{~m}^{2}$ & $\begin{array}{c}\text { Cálculo com } \\
\text { base em } \\
\text { hipótese }\end{array}$ \\
\hline $\begin{array}{c}\text { D - Área de captação da chuva (telhado verde TEVA executado parcialmente nas } \\
\text { coberturas; } 40 \% \text { da área de " } C \text { ") }\end{array}$ & 789.600 & $\mathrm{~m}^{2}$ & $\begin{array}{c}\text { Cálculo com } \\
\text { base em } \\
\text { hipótese }\end{array}$ \\
\hline E - Volume total da água da chuva por dia sobre a área de telhado TEVA & 4.342 .800 & litros/dia* & Calculado \\
\hline
\end{tabular}
simulado em parte das edificações da cidade (" $A$ " $x$ " $D$ ")

Nota: *adota-se o conceito de que cada litro corresponde a 1 (um) mm em medidas pluviométricas, considerando também que índice pluviométrico se refere à quantidade de chuva por metro quadrado em determinado local e período. Fonte: Os autores.

Para o coeficiente de escoamento superficial (Coeficiente de Runoff Racional, que é a razão entre o volume de água escoado superficialmente e o volume de água precipitado) da água de chuva pelo telhado verde a ser utilizado nessa equação foram consideradas duas situações, em função da quantidade de chuva, conforme sugerido no estudo de Robertson et al. (2005) apud Ferreira e Moruzzi, (2007, pp 1031). Na situação classificada como de baixa quantidade de chuva (menor do que $13 \mathrm{~mm} /$ dia) o coeficiente de escoamento superficial da água de chuva pelo telhado verde adotado foi igual a 0,07. No caso da classificação quando há alta quantidade de chuva (entre $25 \mathrm{~mm} /$ dia e 39 $\mathrm{mm} / \mathrm{dia}$ ) o coeficiente de escoamento superficial da água de chuva pelo telhado verde adotado foi igual a 0,25. Na simulação considera-se que essa última situação é representativa para os dias de ocorrência de fortes chuvas na cidade de João PessoaPB. Também se leva em conta que a partir do limite de $20 \mathrm{~mm} / \mathrm{dia}$, como altura da chuva diária para a cidade de João Pessoa-PB, há motivos de preocupações para a defesa civil, devido aos alagamentos frequentes. Neste caso, assume maior importância a análise dos volumes de águas de chuva que possam ser retidos pelos telhados verdes simulados nas coberturas das edificações da cidade, potencializando a redução das descargas no sistema de drenagem pluvial e, consequentemente, as reduções de alagamentos que motivam as preocupações para a defesa civil da cidade.

Portanto, para o cálculo do volume de água escoada pelo telhado verde com blocos TEVA, que foi simulado com instalação sobre pequena área de captação nas coberturas de uma pequena parte das edificações da cidade, foram admitidas duas hipóteses relacionadas entre si: volume de chuva e condição de umidade do solo. Neste caso, a partir dos dados coletados nas coberturas dos protótipos, identificou-se que o solo seco ocorreria para aquele dia com menor quantidade de chuva $(2,6 \mathrm{~mm} / \mathrm{dia})$, antecedido por 3 dias sem ocorrência de chuva; e solo úmido ocorreria na condição do dia com maior quantidade de chuva (6,6 mm/dia), antecedido por 4 dias com ocorrência de chuva. Uma vez encontrados tais valores, foi possível determinar a retenção da água de chuva pelo telhado verde com blocos TEVA, para cada situação (solo seco e úmido), através da subtração do valor total do volume de água da chuva incidente sobre essa cobertura pelo valor da água efetivamente escoada pela mesma cobertura.

\section{Resultados e discussão}

Dentre os 10 dias de eventos de chuvas registrados no período de monitoramento (36 dias) apenas dois dias específicos ( $13^{\circ}$ dia, 29-01-2015 e $36^{\circ}$ dia, 21-02-2015) foram 
identificados com volumes de chuva/dia bem distintos e, principalmente, cada um deles com períodos antecedentes ( 3 e 4 dias anteriores), sem e com ocorrência de chuvas, respectivamente. Contudo, pode-se ver (Tabela 2 ) que os volumes coletados são variáveis e característicos de baixa quantidade de chuva por dia. Então, cada um desses dois dias foi tomado como representativo de cada condição hipotética na análise de escoamento superficial da água de chuva pelo telhado verde com solo seco e úmido, respectivamente. Os referidos dias representativos têm visualização mais fácil na Figura 4, onde são incluídos os registros (INMET, 2016) das chuvas pela estação meteorológica (código OMM: 82798) de João Pessoa, localizada a 9,23 km de distância no local dos protótipos.

$\mathrm{Na}$ Tabela 2, pode-se ver ainda que são apresentados os valores calculados do coeficiente de escoamento superficial da água de chuva para cada cobertura (telhados verdes, telha cerâmica e fibrocimento), considerando a razão entre o volume de água escoado em cada cobertura e aquele volume escoado pela laje exposta e impermeabilizada, que é a cobertura que apresenta o escoamento máximo (CES =1,0). Portanto, deve-se lembrar que o volume escoado superficialmente pela laje impermeabilizada, para efeito dos cálculos, representou o volume de água de chuva precipitado sobre ela. Por sua vez, tal volume de água de chuva precipitado foi considerado igual para todas as coberturas dos protótipos.

\begin{tabular}{|c|c|c|c|c|c|c|c|}
\hline \multirow{2}{*}{$\begin{array}{l}\text { Dias com } \\
\text { destaques nos } \\
\text { registros }\end{array}$} & \multirow{2}{*}{$\begin{array}{l}\text { Condições de umidade dos } \\
\text { materiais (solo e telhas) das } \\
\text { coberturas }\end{array}$} & \multicolumn{6}{|c|}{ Quantidade de água escoada pelas diferentes coberturas } \\
\hline & & $\begin{array}{l}\text { TEVA } \\
\text { Bloco }\end{array}$ & $\begin{array}{c}\text { Bloco } \\
\text { Concreto }\end{array}$ & $\begin{array}{l}\text { Telha } \\
\text { Cerâmica }\end{array}$ & $\begin{array}{c}\text { Telha } \\
\text { fibrocimento }\end{array}$ & $\begin{array}{c}\text { Laje } \\
\text { exposta }\end{array}$ & \\
\hline \multirow{3}{*}{130 dia } & Seco, sem chuva nos dias & 0,5 & 0,8 & 3,0 & 4,8 & 5,3 & litros/dia \\
\hline & antecedentes & 0,28 & 0,45 & 1,69 & 2,71 & 2,99 & (litros $/$ dia) $/ \mathrm{m}^{2}$ \\
\hline & $\begin{array}{l}\text { CES - coeficiente de escoamento } \\
\text { superficial* }\end{array}$ & 0,09 & 0,15 & 0,56 & 0,90 & 1,0 & \\
\hline \multirow{4}{*}{360 dia } & Úmido, com chuva nos dias & 4,0 & 5,3 & 11,0 & 14,5 & 15,0 & litros/dia \\
\hline & antecedentes & 2,26 & 2,97 & 6,21 & 8,19 & 8,47 & (litros/dia)/m² \\
\hline & CES - coeficiente de escoamento & & & & & & \\
\hline & superficial* & 0,26 & 0,35 & 0,73 & 0,96 & 1,0 & \\
\hline
\end{tabular}

A Tabela 3 apresenta uma comparação interessante entre os coeficientes de escoamento superficial (CES) para telhados verdes, tomados como referência (CESreferência), segundo Robertson et al. (2005) apud Ferreira e Moruzzi (2007, pg. 1031) e aqueles obtidos pelos cálculos a partir dos dados registrados nos protótipos (CESprotótipo). O fato notável foi constatar que os valores para CES (referência versus protótipo) resultaram muito parecidos, para a mesma condição de umidade do solo. Neste caso, sugere-se uma correlação entre maior $(6,6 \mathrm{~mm} / \mathrm{dia})$ e menor (2,6 mm/dia) quantidade de chuva com solo úmido e seco, respectivamente, em função dos dias antecedentes com e sem ocorrência de chuvas. Chama-se atenção para o resultado que indica que mesmo em período com baixos volumes de chuvas (o caso do presente estudo), o volume das chuvas acumuladas nos dias antecedentes parece influenciar da mesma forma nos CES do telhado verde. 
MENDONÇA, Tatyane Nadja Martins de; MELo, Aluísio Braz de.

Retenção da Água da Chuva pelo telhado verde com pré-moldado cimentício com EVA

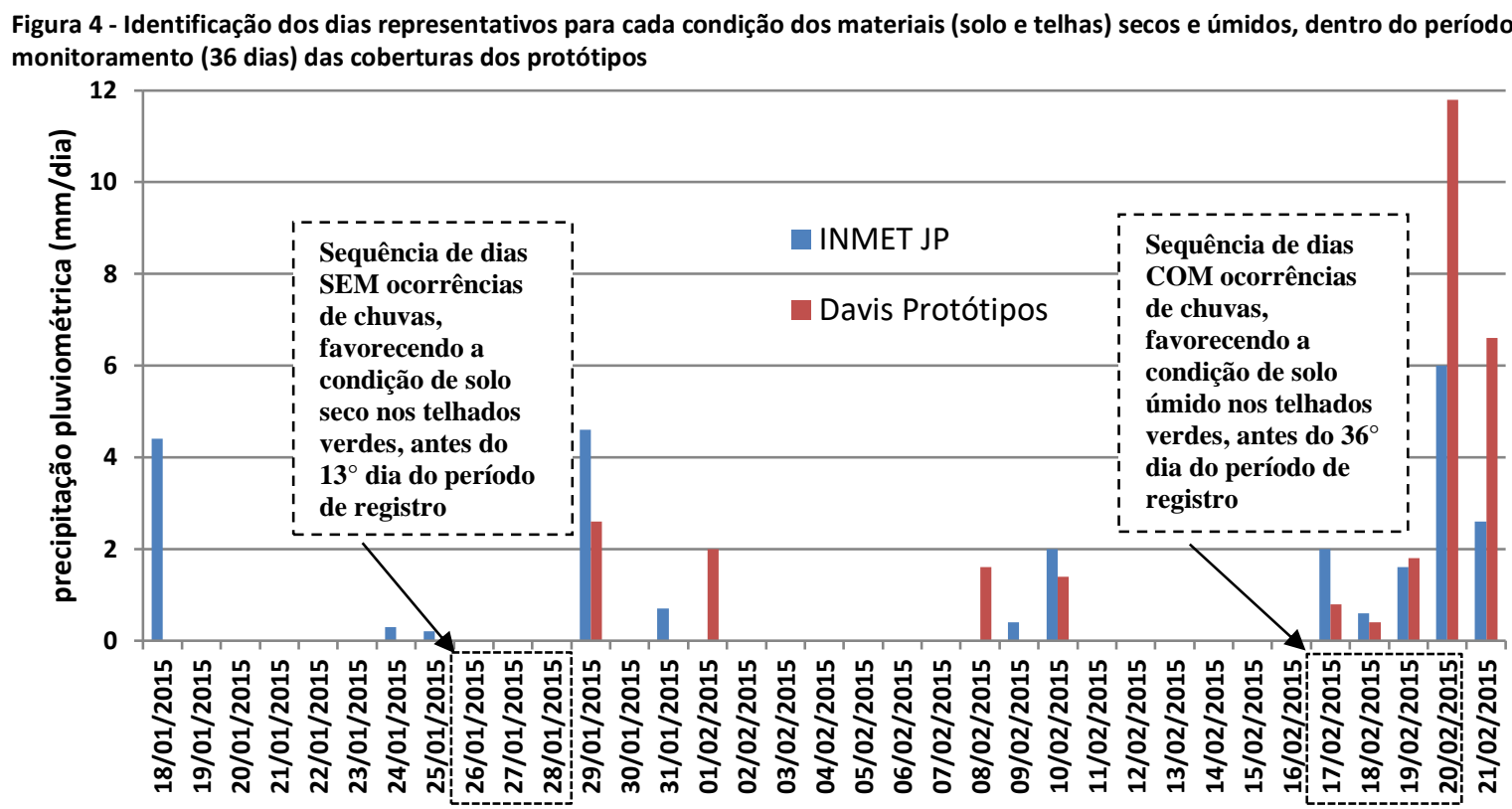

Fonte: Os autores.

Tabela 3 - Comparação entre coeficientes de escoamento superficial (CESreferência versus CESprotótipo), conforme a condição de umidade do solo do telhado verde

\begin{tabular}{|c|c|c|c|c|}
\hline & aração & Volume de chuva/dia & $\begin{array}{l}\text { Condição do solo } \\
\text { considerado }\end{array}$ & CES \\
\hline \multirow{2}{*}{ Referência } & \multirow{2}{*}{$\begin{array}{l}\text { Robertson et al. (2005) apud } \\
\text { Ferreira e Moruzzi (2007, pp. } \\
\text { 1031) }\end{array}$} & $\begin{array}{l}\text { Baixo volume de chuva } \\
\text { (menor do que } 13 \mathrm{~mm} / \text { dia) }\end{array}$ & seco & 0,07 \\
\hline & & $\begin{array}{l}\text { Alto volume de chuva (entre } \\
25 \text { e } 39 \mathrm{~mm} / \mathrm{dia})\end{array}$ & úmido & 0,25 \\
\hline \multirow{2}{*}{ Protótipo } & \multirow{2}{*}{$\begin{array}{l}\text { Protótipos com telhado verde } \\
\text { com blocos TEVA (calculados } \\
\text { a partir dos dados da Tabela } \\
\text { 2) }\end{array}$} & $\begin{array}{c}\text { Menor volume de chuva }(2,6 \\
\mathrm{mm} / \text { dia - } 29 / \mathrm{jan} / 2015) \text {, sem } \\
\text { chuva nos } 3 \text { dias } \\
\text { antecedentes sobre os } \\
\text { protótipos }\end{array}$ & seco & 0,09 \\
\hline & & $\begin{array}{l}\text { Maior volume de chuva }(6,6 \\
\text { mm/dia - } 21 / \text { fev/2015), com } \\
\text { chuva nos } 4 \text { dias } \\
\text { antecedentes sobre os } \\
\text { protótipos }\end{array}$ & úmido & 0,26 \\
\hline
\end{tabular}

Fonte: Os autores.

A análise para as diferentes condições de umidade nos materiais presentes nas respectivas coberturas comparadas (Telhado verde com blocos TEVA, Telhado verde com blocos concreto, telha cerâmica e telha fibrocimento) pode ser vista na Figura 5 .

Os resultados confirmam que os telhados verdes comparados às coberturas convencionais (com telha cerâmica e fibrocimento) possuem menor escoamento de água de chuva, portanto, maior capacidade de retenção da água de chuva, independente da condição de umidade nos materiais presentes nas respectivas coberturas. Mas, em todos os casos, os percentuais de água de chuva escoados pelas coberturas são maiores quando os materiais ali existentes estão em condição úmida. Como esperado, a cobertura com telha cerâmica se apresenta com menores escoamentos da água de chuva, quando comparada àquela com telha de fibrocimento, para ambas as condições de umidade das telhas. Certamente, a diferença caraterística na absorção de água pelos dois materiais (cerâmica e fibrocimento) justifica os resultados encontrados. 
Figura 5 - Escoamento da água de chuva pelos telhados verdes (blocos TEVA e Concreto) e coberturas convencionais (telhas cerâmica e fibrocimento) instaladas em protótipos para condições diferentes de umidade no solo e nas telhas

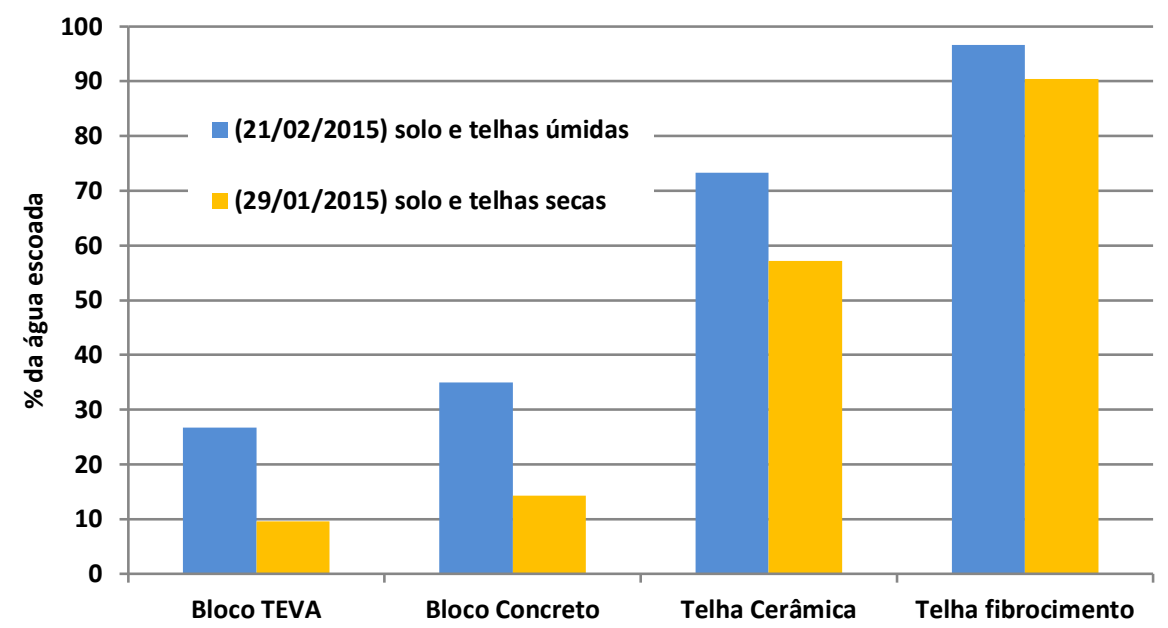

Fonte: Os autores

Na comparação entre os dois telhados verdes (blocos TEVA e blocos concreto) pode-se notar que aquele com blocos TEVA tem menor percentual de escoamento da água de chuva ( $9,5 \%$ com solo seco e $26,7 \%$ com solo úmido), portanto, maior capacidade de retenção da água de chuva ( $90,5 \%$ com solo seco e $73,3 \%$ com solo úmido), em qualquer condição de umidade do solo (substrato). Neste caso, como justificativa para essa maior retenção das águas de chuva atribui-se à contribuição adicional dos agregados de EVA (resíduo da indústria de calçados) presentes nos blocos TEVA, que inclusive teve maior absorção de água (19,5\%), cerca de três vezes maior do que a registrada pelo bloco de concreto (6,2\%). O interessante é que isso ocorre apesar dos blocos TEVA também facilitarem a drenagem do eventual excesso de água no substrato, como visto na imagem da Figura 1 a direita.

Tais resultados estão de acordo com os estudos desenvolvidos por Jobim (2013), que comparou diferentes sistemas de coberturas e suas capacidades de retenção da água pluvial e concluiu que o telhado verde modular com os blocos de EVA (intitulado como módulo galocha) foi o mais promissor. Com relação à capacidade de retenção dos telhados verdes, os estudos de Van Woert et al. (2005) apontam para valores de 82,5\%; nos desenvolvidos por Tassi et al. (2014) alcançou-se 62\%; naquele estudo de Jobim (2013) foi encontrado 82,8\%; enquanto DeNardo et al. (2005), encontraram uma variação entre $19 \%$ e $98 \%$. Como se pode ver, há variações para cada estudo, sendo importante que na caracterização da capacidade de retenção da água de chuva pelo telhado verde seja considerada a condição de umidade do solo, entre outras variáveis. De certa forma, os estudos de Jobim (2013), Van Woert (2005) e Tassi et al. (2014) confirmam altas capacidades de retenção da água da chuva da mesma forma como também foram encontrados valores altos no presente estudo, sendo o de Jobim (2013) aquele que mais se aproxima em termos de valor e característica do material testado no telhado verde.

Com relação às simulações para as estimativas dos volumes da água de chuva escoada e retida pelos telhados verdes com blocos TEVA, na escala da cidade de João Pessoa-PB, os resultados para os volumes de água de chuva por dia, retida e escoada pelos telhados verdes, na condição de solo seco e úmido, são apresentados na Figura 6, onde se pode constatar que os valores são próximos para ambos os coeficientes de escoamento superficial (CESreferência e CESprotótipo) adotados nos cálculos.

A análise geral dos dados confirma que a capacidade de retenção da água de chuva é maior à medida que o sistema (bloco TEVA e substrato) está mais seco; por outro lado, 
quando esse sistema está úmido, devido à ocorrência de chuvas nos 3 dias antecedentes, essa capacidade de retenção da água de chuva diminui. Contudo, fica bem caracterizada a capacidade para o telhado verde modular extensivo, executado com blocos TEVA, na retenção de grandes volumes de água de chuva (cerca de 4 milhões de litros/dia) na condição de solo seco. Naquelas ocasiões de ocorrência de alta quantidade de chuva por dia, que normalmente são motivo de preocupações para a defesa civil, certamente tais volumes retidos pelo telhado TEVA poderia reduzir os impactos no sistema de drenagem urbana. Mesmo na condição de solo úmido aqui analisada, percebe-se que é significativo o volume de água de chuva retida por esse telhado (cerca de 3,2 milhões de litros/dia). Deve-se lembrar de que a escala da simulação adotada com aplicação desse telhado verde para João Pessoa-PB é muito reduzida, pois apenas uma parte (30\% das coberturas das edificações verticalizadas e com o telhado verde ocupando somente $40 \%$ de tais coberturas), de uma pequena parcela (3,12\%) da área territorial da cidade (como projeção das construções, ou seja, áreas das coberturas) foi considerada nos cálculos para efeito da área de captação da água da chuva.

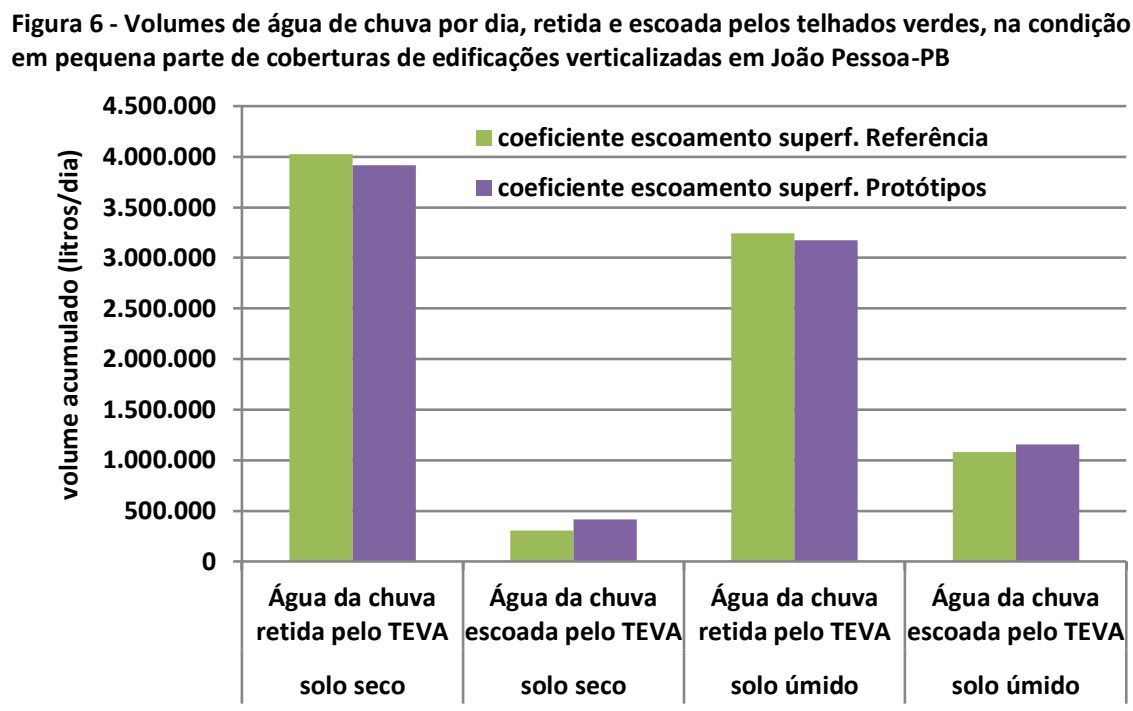

Fonte: Os autores

Simulações de cenários semelhantes para cidades maiores como Recife-PE, São PauloSP etc., que têm recorrentes problemas de alagamento nas vias urbanas, em dias de fortes chuvas, poderia revelar maiores contribuições para os valores de retenção das águas de chuva pelo telhado verde proposto. Cabe ressaltar, que a simulação realizada está coerente com legislações urbanísticas, que têm obrigado em algumas cidades brasileiras a execução de telhado verde em edifícios verticalizados, sejam habitacionais multifamiliares, com mais de 4 pavimentos, ou mesmo não habitacionais, estabelecendo requisito pelo limite da área da cobertura.

\section{Conclusão}

A partir da análise dos resultados obtidos nas medições em protótipos e na simulação do uso do telhado verde proposto com blocos TEVA em pequena quantidade de coberturas de edificações de uma cidade porte médio, procurou-se caracterizar a retenção de água da chuva pela referida cobertura, destacando-se os seguintes pontos:

- o telhado verde proposto (blocos TEVA), comparado às coberturas convencionais (com telha cerâmica e fibrocimento) possui maior capacidade de retenção da água de 
chuva, independente da condição de umidade nos materiais presentes nas respectivas coberturas;

- a condição de umidade do solo interfere na capacidade de retenção da água da chuva, podendo no caso do telhado verde com os blocos TEVA propostos variar entre 90,5\%, quando o solo está seco, e 73,3\%, quando o solo está úmido;

- a presença dos agregados de EVA (resíduo da indústria de calçados) nos blocos TEVA contribui adicionalmente na retenção das águas de chuva;

- o telhado verde modular extensivo com blocos TEVA, na hipótese de ocupar parcialmente coberturas de edifícios de João Pessoa-PB, tem capacidade de reter grandes volumes de água de chuva por dia (cerca de 4 milhões de litros/dia) na condição de solo seco.

\section{Agradecimentos}

A CAPES pelo financiamento parcial da presente pesquisa e aos Laboratórios da Instituição (UFPB) que deram suporte para a realização dessa pesquisa.

\section{Referências}

ABNT - ASSOCIAÇÃO BRASILEIRA DE NORMAS TÉCNICAS. NBR 12118: Blocos vazados de concreto simples para alvenaria - Métodos de ensaio. Rio de Janeiro, 2014. Disponível em:

http://www.abntcatalogo.com.br/norma.aspx?ID=314197;

ABNT - ASSOCIAÇÃO BRASILEIRA DE NORMAS TÉCNICAS. NBR 15527: Água de chuva - Aproveitamento de coberturas em áreas urbanas para fins não potáveis - Requisitos - Rio de Janeiro, 2007. Disponível em: http://www.abntcatalogo.com.br/norma.aspx?ID=325;

BERARDI, Umberto; GHAFFARIANHOSEINI, Amir Hosein; GHAFFARIANHOSEINI, Ali. State-of-the-art analysis of the environmental benefits of green roofs. Applied Energy, v.115, p.411-428, feb. 2014.

DOI:http://dx.doi.org/10.1016/j.apenergy.2013.10.047;

CASTLETON, H.F.; STOVIN, V.; BECK, S.B.M.; DAVISON, J.B. Green roofs; Building energy savings and the potential for retrofit. Energy and Buildings, v.42, Issue 10, p.1582-1591, oct. 2010.

DOI:https://doi.org/10.1016/j.enbuild.2010.05.004;

DEL BARRIO, E. P. Analysis of the green roofs cooling potential in buildings. Energy and Buildings, v.27, Issue 2, p.179-193, apr. 1998. DOl:https://doi.org/10.1016/S0378-7788(97)00029-7;

DENARDO, J.C., JARRETT, A.R., MANBECK, H.B., BEATTIE, D.J., BERGHAGE, R.D. Stormwater mitigation and surface temperature reduction by green roofs. Transactions of the American Society of Agricultural and Biological Engineers, v. 48, n. 4, p. 1491-1496, 2005. DOI:https://doi.org/10.13031/2013.19181.

DINIZ, Júlio Mannuel Tavares. Variabilidade da precipitação e do número de dias com chuvas de duas cidades distintas da Paraíba. HOLOS. v.3, p. 171-180, jun. 2013. DOI: https://doi.org/10.15628/holos.2013.1291

DUNNETT, N.; NAGASE, A.; HALLAM, A. The dynamics of planted and colonising species on a green roof over six growing seasons 2001-2006: Influence of substrate depth. Urban Ecosystems, v. 11, n. 4, p. 373-384, dec.2008. DOI:https://doi.org/10.1007/s11252-007-0042-7

FERREIRA, C. A.; MORUZZI, R. B. Considerações sobre a aplicação do telhado verde para captação de água de chuva em sistemas de aproveitamento para fins não potáveis. In: ENCONTRO NACIONAL, 4; ENCONTRO LATINOAMERICANO SOBRE EDIFICAÇÕES E COMUNIDADES SUSTENTÁVEIS, 2., 2007, Campo Grande. Anais [...]. Campo Grande: ELECS, 2007, p.1027-1036; 
INMET. Instituto Nacional de Meteorologia. BDMEP. Banco de Dados Meteorológicos para Ensino e Pesquisa. Disponível em: http://www.inmet.gov.br/projetos/rede/pesquisa/. Acesso em 18 agosto 2016;

JAFFAL, I.; OULDBOUKHITINE, S.; BELARBI. R. A comprehensive study of the impact of green roofs on building energy performance. Renewable Energy, v.43, p. 157-164, jul. 2012. DOI:https://doi.org/10.1016/j.renene.2011.12.004

JOBIM, A. Diferentes tipos de telhados verdes no controle quantitativo da água pluvial. 2013, $75 f$. Dissertação (Mestrado) - Programa de Pós-Graduação em Engenharia Civil, Universidade Federal de Santa Maria, Santa Maria, 2013.

KÖHLER, M. Long-Term Vegetation Research on Two Extensive Green Roofs in Berlin. Urban Habitats. v.4, n. 1, p. 326. dec. 2006.

KÖHLER, M., POLL, P.H. Long-term performance of selected old Berlin greenroofs in comparison to younger extensive greenroofs in Berlin. Ecological Engineering, v.36, n. 5, p. 722-729, 2010.

DOI:https://doi.org/10.1016/j.ecoleng.2009.12.019

MENDONÇA, Tatyane Nadja Martins de. Telhado verde extensivo em pré-moldado de concreto EVA (Acetato Etil Vinila). 2015, 210f. Dissertação (Mestrado) - Programa de Pós-Graduação em Engenharia Civil e Ambiental, Universidade federal da Paraíba, João Pessoa, 2015;

MENDONÇA, Tatyane Nadja Martins; MELO, Aluísio Braz de. Telhado verde modular extensivo: biodiversidade e adaptação das plantas aos Blocos TEVA. PARC Pesquisa em Arquitetura e Construção, Campinas, SP, v. 8, n. 2, p. 117-126, jun. 2017. DOI:http://dx.doi.org/10.20396/parc.v8i2.8649606

MENTENS, J., RAES, D., HERMY, M. Green roofs as a tool for solving the rainwater runoff problem in the urbanized 21st century? Landscape and Urban Planning, v. 77, n. 3, p. 217-226, aug. 2006.

DOI:https://doi.org/10.1016/j.landurbplan.2005.02.010

NIU, H.; CLARK, C.; ZHOU J.; ADRIAENS, P. Scaling of economic benefits from green roof implementation in Washington, DC. Environmental Science \& Technology, v. 44, n. 11, p. 4302-4308, apr. 2010.

DOI:https://doi.org/10.1021/es902456x

OBERNDORFER, E; LUNDHOLM, J; BASS, B; COFFMAN, R.R; DOSHI, H; DUNNETT, N; GAFFIN, S; KÖHLER, M; LIU, K.K.Y; ROWE, B. Green roofs as urban ecosystems: ecological structures, functions, and services. BioScience, v.57, n.10, p. 823-833, nov. 2007. DOI:https://doi.org/10.1641/B571005

OHNUMA, A. A. Medidas não convencionais de reservatório d'água e controle da polução hídrica em lotes domiciliares. 2008. 306f. Tese (Doutorado em Ciências da Engenharia Ambiental) - Escola de Engenharia de São Carlos. São Paulo, 2008;

OULDBOUKHITINE, S. E.; BELARBI, R.; JAFFAL, I.; TRABELSI, A. Assessment of green roof thermal behavior: A coupled heat and mass transfer model. Building and Environment, v.46, n. 12, p. 2624-2631, dec. 2011. DOI:https://doi.org/10.1016/j.buildenv.2011.06.021

RIBEIRO, C. A. M. Atualização e aprofundamento do mapa de análises climáticas do município de João Pessoa Paraíba. 2013. 157f. Dissertação (Mestrado) - Programa de Pós-Graduação em Arquitetura e Urbanismo. Universidade Federal da Paraíba, João Pessoa, 2013;

TASSI, Rutinéia et al . Telhado verde: uma alternativa sustentável para a gestão das águas pluviais. Ambient. constr., Porto Alegre, v. 14, n. 1, p. 139-154, Mar. 2014 . DOI: https://doi.org/10.1590/S1678-86212014000100012.

THEODOSIOU, T.G. Summer period analysis of the performance of a planted roof as a passive cooling technique. Energy and Buildings, v.35, n. 9, p. 909-917, oct. 2003. DOl:https://doi.org/10.1016/S0378-7788(03)00023-9. 
TONIETTO, R.; FANT, J.; ASCHER, J.; ELLIS, K.; LARKIN, D. A comparison of bee communities of Chicago green roofs, parks and prairies. Landscape and Urban Planning, v.103, Issue 1, p. 102-108, oct. 2011.

DOI:https://doi.org/10.1016/j.landurbplan.2011.07.004

VAN WOERT, N.D.; ROWE, D.B.; ANDRESEN, J.A.; RUGH, C.L.; FERNANDEZ, R.T.; XIAO, L. Green roof storm water retention: Effects of roof surface, slope, and media depth. Journal of Environmental Quality, v.34, n.3, p. 1036-1044, may 2005. DOI:https://doi.org/10.2134/jeq2004.0364;

VECCHIA, F. Cobertura Verde Leve (CVL): Ensaio Experimental. In: ENCONTRO NACIONAL DE CONFORTO NO AMBIENTE CONSTRUÍDO (ENCAC), 6; ENCONTRO LATINO-AMERICANO SOBRE CONFORTO NO AMBIENTE CONSTRUÍDO, 4., Maceió. Anais [...]. Maceió: ANTAC, 2005;

WILLIAMS, N.S.G.; RAYNER, J.P.; RAYNOR, K.J. Green roofs for a wide brown land: opportunities and barriers for rooftop greening in Australia. Urban Forest \& Urban Green, v.9, Issue 3, p. 245-251, 2010.

DOI:https://doi.org/10.1016/j.ufug.2010.01.005.

\section{${ }^{1}$ Tatyane Nadja Martins de Mendonça}

Bióloga pela Universidade Federal da Paraíba. Mestre em Engenharia Civil e Ambiental/UFPB. Rua Radialista Antônio Assunção de Jesus, 89, João Pessoa, Paraíba, Brasil, 58052-230

\section{${ }_{2}^{2}$ Aluísio Braz de Melo}

Arquiteto pela Universidade Federal da Paraíba. Doutor em Ciência e Engenharia de Materiais/EESC-USP. Avenida Guarabira, 1125, João Pessoa, PB, Brasil, 58038-142. 